\title{
DEBATE CONCEITUAL SOBRE VULNERABILIDADE SOCIAL E SUSPECTIBILIDADE AOS RISCOS
}

\author{
Ítalo Renan Ferreira Girão ${ }^{(a)}$ \\ (a) Mestrando em Desenvolvimento e Meio Ambiente, Departamento de Geografia, Universidade Federal do Ceará - \\ UFC, italorgirao@gmail.com
}

\section{Eixo: GEOGRAFIA FÍSICA E DESASTRES NATURAIS}

\begin{abstract}
Resumo
Considerando o conceito de risco e da forma de organização e ocupação do espaço, a situação de vulnerabilidade está posta nas diversas realidades. Condições sociais e econômicas constituem-se como elementos variáveis para determinação das vulnerabilidades sociais, sendo a fragilidade natural um fator que acentua tal condição. Tais elementos variáveis são, portanto, fatores de influencia para maior ou menor condição do estar vulnerável e da susceptibilidade. Propõe-se realizar a revisão bibliográfica dos conceitos inerentes, com vistas à percepção do quanto a interação entre os elementos sociais e ambientais contribuem para determinar a vulnerabilidade socioambiental. Para tanto, apresenta-se várias abordagens e linhas de pensamentos de autores que já exploraram a temática inerente aos riscos, tendo como resultado uma revisão bibliográfica sobre os conceitos que servirão como base para a construção de estudos sobre vulnerabilidade e susceptibilidades. A pesquisa consolida-se como um material útil para ações de planejamento e gestão ambiental do território.
\end{abstract}

Palavras chave: Revisão bibliográfica; Riscos; Sociedade; e, Meio Ambiente.

\section{Introdução}

Não obstante a construção de um debate sobre modelos de desenvolvimento socioambiental, o presente trabalho remete-se a uma discussão teórica sobre a organização socioespacial do. Sabe-se que a interação entre os diversos fatores ambientais, a saber: orogênese, morfogênese, clima, condições pedológicas, características fitoecológicas, dentre outros aspectos, incidem sobre a realidade, consolidando condições de maior ou menor vulnerabilidade das sociedades, bem como susceptibilidade dos ambientes naturais.

Uma área de estudo necessariamente possui características naturais que são reflexo dos elementos dominantes no ato de sua gênese, ou mesmo no processo de sua formação, modelagem e transformação. Dentro de um discurso exclusivamente ambiental, diagnosticar uma área significa descrever suas particularidades e entender o processo que resultou nas mesmas. Saber diferenciar os ambientes naturais possibilita comparar e estipular quais são mais frágeis e/ou instáveis que outros. É natural encontrar ambientes que ainda estão em processo de formação ou cujas características apontam para uma necessidade de não intervenção. 
Porém, ao tratar-se de meio ambiente, separar a vertente humana do natural consolida-se como um erro grosseiro. Sendo o homem o principal agente transformador da natureza, diversas condições de instabilidade e fragilidade são criadas, nem tanto pelo fator natural, mas, pelo uso e ocupação antrópica. Dessa forma, incorporar o conceito de vulnerabilidade é uma estratégia positiva para a realização de planejamentos ambientais, uma vez que a condição de vulnerabilidade é maior ou menor conforme as características do ambiente, das condições socioeconômicas e da forma de uso e ocupação do meio. Vale diferenciar e explorar também o conceito de susceptibilidade, numa perspectiva de ampliação dos conceitos.

A forma como o homem gera instabilidade ambiental - susceptibilidade - está intimamente relacionada à forma como ele ocupa o espaço. Nesse debate, não se pode deixar de lado o conceito sobre degradação ambiental, como um fator exclusivamente antrópico, bem como o quão propício está o ambiente natural à instabilidade gerada pelo homem, dadas suas características naturais.

\section{O que é risco? O que é perigo?}

Ao se falar de risco, é inevitável dar-se uma conotação negativa, prevalecendo o aspecto do ruim que pode acontecer. É raro associar esse conceito a algo positivo. Assim, termos como: "risco de enriquecer", "risco de vitória" etc. são expressões pouco ou não usadas. Entende-se que é usual tal associação por ser a expressão risco um termo ainda não amplamente debatido, apesar de amplamente usado.

O conceito de risco, grosso modo, está relacionado ao sentido de imprevisibilidade ou a probabilidade de algo acontecer. Porém, a constante associação ao conceito de perigo, torna o risco um elemento de imprevisibilidade correlacionado ao expor-se ao dano, ao ruim, ao severo. Apresenta-se, em tempo, Aurélio Buarque de Holanda Ferreira, cujo dicionário online registra o termo Risco como sendo: exposição ao Perigo; inconveniente. (DICIONÁRIO AURÉLIO, 2016).

Diversas interpretações e designações, bem como os variados trabalhos insurgentes relacionados ao conceito, tem favorecido um maior aprofundamento sobre a temática. Tais recentes trabalhos não podem, entretanto, serem considerados pioneiros, haja vista que desde a Antiga Babilônia já haviam assessores profissionais para a análise de riscos, especialmente os ambientais (AUGUSTO FILHO, 2001 apud MENEZES JÚNIOR \& SILVA, 2016). Já para Veyret, o termo risco dada desde o Renascimento italiano, valorizando posteriormente em outros países, dado o aumento da demanda por segurança associada a necessidade de aumento da qualidade de vida (VEYRET, 2007 apud MENEZES JÚNIOR \& SILVA, 2016). 


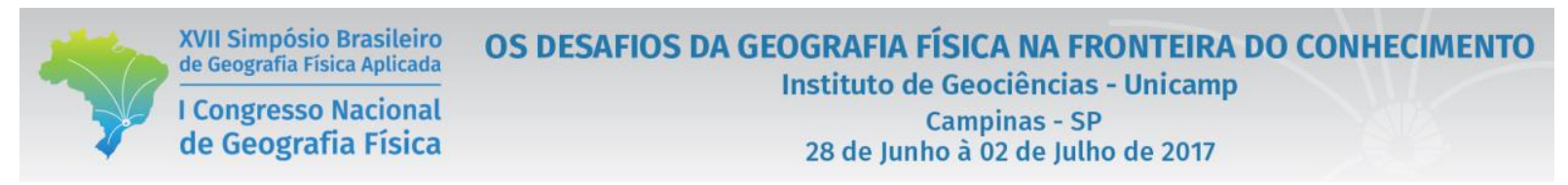

Ou seja, não é de hoje que há preocupação do homem com o conhecimento e o domínio do risco. Isso significa que o arcabouço teórico para definição do termo risco é amplo, possibilitando uma variedade de fontes de consulta.

Há várias maneiras de definir os conceitos de risco [...], devido às diversas áreas de conhecimento que fazem uso deles, porém, a abordagem dá-se através de perspectivas diferenciadas. [...] o risco como conceito parte do discurso linguístico, tem-se constituído na trajetória histórica e cultural das sociedades e deve ser sempre pensado como processo e não como variável em si (JANCZURA, 2012, p. 302).

Isso deve ser considerado positivo, mas em termos de construção de uma linha de definição conceitual e epistemológica, as diferentes traduções e definições podem gerar linhas de desentendimento para uma apropriação mais ampla (MENEZES JÚNIOR \& SILVA, 2016).

A noção de risco é complexa. Discute-se a origem do termo "risco", presente em todas as línguas europeias (inglês: risk, italiano: rischio, espanhol: riza). Ela pode ser oriunda tanto dos termos latinos como rixare, significando "brigar", ou resecare, "extirpar, suprimir", quanto do grego rhizikon ou, ainda, do árabe, risk. Muito cedo, na Itália, o termo designa "escolho", depois "naufrágio" e, em seguida, um perigo possível do qual o armador pode ser vítima. De fato, a palavra designa, ao mesmo tempo, tanto um perigo potencial quanto sua percepção, e indica uma situação percebida (VEYRET \& RICHEMOND, 2007).

Partindo da citação acima exposta, percebe-se que a correlação entre os conceitos de Risco e Perigo é bastante próxima. Menezes Júnior \& Silva (2016), ao apresentar os estudos elaborados por Marandola Jr. e Hogam nos anos de 2003 e 2004, referencia no seu artigo que

o perigo está se confundindo com o hazards [risco - tradução nossa], sendo este definido por eventos naturais que desestabilizam um ciclo natural conhecido pela sociedade: terremotos, erupções vulcânicas, furacões etc. enquanto que o perigo se insere quando a população se torna susceptível a determinado evento por ter conhecimento da ocorrência. Logo, a sociedade estaria em perigo (MARANDOLA JR; HOGAM, 2003; 2004a; 2004b; 2004c apud MENEZES JÚNIOR \& SILVA, 2016).

É uma proximidade conceitual que é diferenciada apenas pelo agente provocador e/ou de susceptibilidade. Para tal autor, portanto, Risco está associado aos eventos naturais que provocam o infortúnio, enquanto Perigo está posto num contexto social, associando-se, assim, ao fato do ser humano (e sua organização enquanto sociedade) estar susceptível (ou provocar) o evento infortúnio. A própria Nações Unidas (ONU) corrobora essa visão conceitual ao apresentar a definição de risco como: "grado de pérdida previsto debido a un fenómeno natural determinado y en función tanto del peligro natural como de la vulnerabilidad" (NACIONES UNIDAS, 1984, p. 80).

Porém, quando se parte dessa ideia relacional, expõe-se o erro de desconsiderar o aspecto social como elemento de risco, bem como o aspecto natural associado ao perigo. Dessa forma, como explicar, por exemplo, o risco social no qual famílias carentes, ou que não possuem condições de moradia e acesso a bens e serviços básicos que oportunizem melhores condições de enfrentamento ao infortúnio, estão 
expostas? É possível excluir os elementos sociais de uma análise dos riscos e da exposição de pessoas e comunidades aos mesmos?

Para Carneiro e Veiga (2004 apud JANCZURA, 2012, p. 304), é a pobreza o elemento principal para uma maior exposição aos riscos, principalmente num contexto de ausência de proteção e seguridade social.

A ausência de recursos materiais alimentará outras fragilidades: baixa escolarização, condições precárias de saúde e de nutrição, moradias precárias em locais ambientalmente degradados e condições sanitárias inadequadas (necessidades insatisfeitas). Famílias e pessoas em tais condições de vida disporão de um repertório mais reduzido para enfrentar as adversidades (JANCZURA, 2012, p. 304).

Considerando-se, portanto, que o risco é a situação onde pessoas e/ou o meio ambiente está exposto à susceptibilidade de ocorrência do dano ou do evento infortúnio, levanta-se as seguintes observações:

I - Seres humanos e o meio ambiente estão vulneráveis e susceptíveis à maior ou menor exposição ao risco, sendo as características sociais e/ou as condições ambientais/naturais as variáveis (fatores) para determinação e mensuração dessa susceptibilidade;

II - A percepção de riscos consolida-se como uma estratégia metodológica, datada do início do século XX, cuja avaliação empírica dá-se por meio da construção de diferentes categorias de manifestação (SOUZA \& ZANELLA, 2009, pp. 29-30); e,

III - O desastre é a consequência e/ou o efeito gerado num contexto de maior risco, resultante da consolidação prática da ameaça (perigo), caracterizada, necessariamente, como negativo.

Outrossim, no que tange o aspecto natural associado ao perigo, como desconsiderar os fenômenos naturais extremos que, ao consolidar-se, ameaçam a vida humana? Fenômenos naturais extremos são plenamente possíveis de ocorrer e a sua ocorrência, numa situação ou num espaço geográfico habitado por sociedades e/ou ambientes vulneráveis, consolida a existência do perigo à vida humana. Dessa forma, não se pode excluí-la (a ocorrência de eventos naturais extremos) do debate sobre perigo.

Um perigo natural é um fenômeno natural extremo que ameaça vidas humanas, atividades, bens ou o ambiente. Sua presença é constante ou está sujeita a flutuações. Muitos deles são cíclicos, como os tremores de terra associados à acumulação gradual de pressão sobre uma falha. Outros, especialmente os meteorológicos, tendem a ser sazonais. Fenômenos naturais podem ser transformados em perigo, quer por excesso quer por falta (LICCO \& SEO, 2013).

Assim, tanto os elementos de ordem natural como social contribuem para uma maior exposição aos riscos, bem como existência do perigo nos diversos contextos modernos. Dessa forma, a necessária ampliação dos conceitos de risco e perigo remete para uma sintetização dos conceitos que esteja próximo de uma definição que siga uma linha de raciocínio que considere a diversidade e a complexidade dos mesmos. Num contexto de sociedade contemporânea, risco e perigo estão muito próximos, porém não devem ser 
considerados a mesma coisa, estando o risco mais para a situação probabilística de ocorrência do evento indesejado, levando em consideração o quão susceptível ou exposto está o indivíduo e/ou a comunidade.

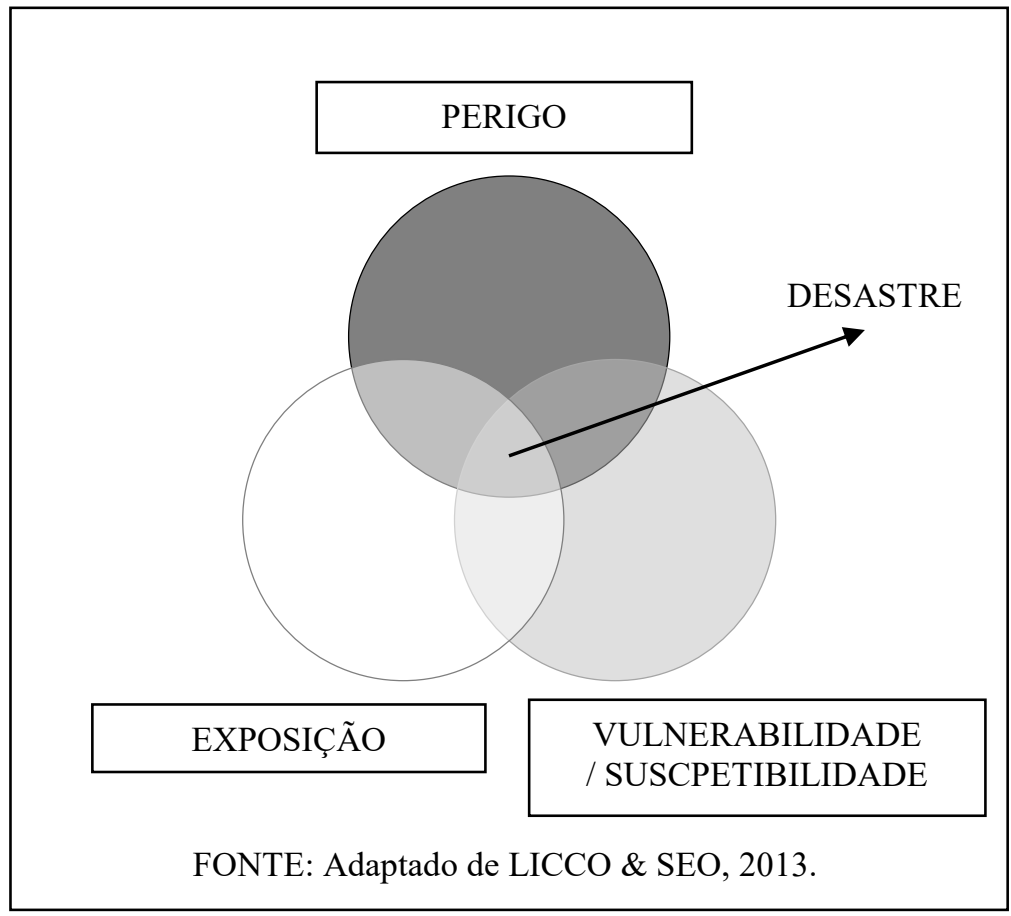

Figura 1: Diagrama de análise da relação entre Perigo, Exposição e Vulnerabilidade como elementos de interseção do desastre.

Trazendo o diálogo proposto por Almeida (2010), quando o autor apresenta a ideia da onipresença do risco e do perigo nas sociedades modernas, é notório perceber o motivo pelo qual o homem associa risco ao perigo, numa correlação intrínseca. A presença cotidiana do risco na vida do ser humano dá-se pelo simples fato do mesmo não conseguir controlá-lo plenamente. O homem sempre está na companhia do perigo, sendo tal situação uma inerência à própria vida (ALMEIDA, 2010). Acompanhar-se do perigo, mesmo que indesejadamente, significa estar exposto às situações de risco, necessariamente.

Dessa forma, começa-se a perceber que os conceitos de risco e perigos não podem ser traduzidos como sendo a mesma coisa, apesar da relação entre tais conceitos serem bem próximas.

Castro (2000), na tentativa de apresentar o conceito de risco, traz-se a definição apresentada pela Real Academia Española: "implica la proximidad de un daño, desgracia o contratiempo que puede afectar la vida de los hombres" (Real Academia Española, 1992, p. 1562 apud CASTRO, 2000, p. 2).

Lutiane Queiroz de Almeida, ao fazer uma discussão sobre a ciência dos riscos e vulnerabilidades dentro da Geografia, aponta o conceito de risco como sendo:

De forma geral [...] o conceito de risco pode ser tomado como categoria de análise associada às noções de incerteza, exposição ao perigo, perda e prejuízos materiais e 


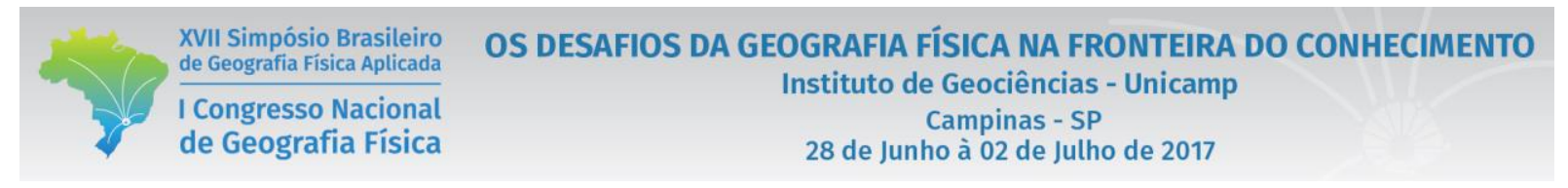

humanos, atrelados não só a processos naturais, mas também a processos oriundos das atividades humanas. (ALMEIDA, 2011, v. 10, p. 85).

Para o autor, a tentativa de domínio do risco pelo homem consolida-se como o marco histórico entre os limites da Modernidade e do anterior, uma vez que o risco sempre esteve onipresente à existência humana e que a partir do domínio do risco o homem passa a não submeter-se ao divino acaso ${ }^{1}$ (ALMEIDA, 2010, v. 10, p. 84). Com o surgimento de novas técnicas e tecnologias, bem como da industrialização dos processos produtivos, têm-se a ilusão de que o homem passa a dominar a natureza e os riscos passam a ser controlados e minimizados. Porém, é na modernidade e na pós-modernidade (século XX em diante) que se verifica e passa-se a registrar eventos catastróficos de ordem natural e social (ALMEIDA, 2010, v. 10, p. 84) que revelam a completa incapacidade humana de gerenciar riscos, prevenir perigos e diminuir vulnerabilidades.

Dessa forma, a modernidade que deveria ser marcada pelo domínio do risco pelo homem acaba por consolidar-se como um período do risco.

Nesse momento, generalizam-se os chamados perigos tecnológicos (technological hazards) [...]. Quanto aos os perigos naturais (natural hazards) [...] se repetem com frequiência e magnitudes cada vez mais devastadoras, tanto em função das mudanças ambientais empreendidas pelo homem, quanto pela crescente concentração de populações cada vez mais vulneráveis nas cidades, pelo crescimento demográfico, e pela globalização das desigualdades e segregação sociais (ALMEIDA, 2010, v. 10, p. 84).

Para Castro, 2000, o conceito de risco perpassa, portanto:

Los riesgos implican un mayor grado de controversia científica que los peligros, tanto respecto de sus causas como de sus consecuencias y probabilidades de ocurrencia. La acepción más divulgada de riesgo es la de peligro que se corre. En líneas generales coincidiría con la acepción dada en este trabajo a la palabra riesgo: es la probabilidad de ocurrencia de un peligro. El concepto incluye la probabilidad de ocurrencia de un acontecimiento natural o antrópico y la valoración por parte del hombre en cuanto a sus efectos nocivos (vulnerabilidad). La valoración cualitativa puede hacerse cuantitativa por medición de pérdidas y probabilidad de ocurrencia. Cuando se cuenta con los datos adecuados para realizar un cálculo de probabilidades se puede definir el riesgo. En cambio, cuando no existe posibilidad de calcular probabilidades, sino que solo existe intuición o criterio personal, se está frente a una incertidumbre (CASTRO, 2000).

Quanto ao perigo, o mesmo autor afirma: "peligro es la ocurrencia o amenaza de ocurrencia de un acontecimiento natural o antrópico. Esta definición de peligro se refiere al fenómeno tanto en acto como en potencia" (CASTRO, 2000). Ou, como resumo gráfico, expõe o seguinte:

\footnotetext{
${ }^{1}$ Até então, associava-se os eventos de risco aos desejos e castigos divinos, colocando o homem como um ser passivo diante de uma natureza vingativa. Formas de culto e construção de Igrejas eram as principais estratégias para combater tais eventos (BERNSTEIN, 1998 apud ALMEIDA, 2010).
} 


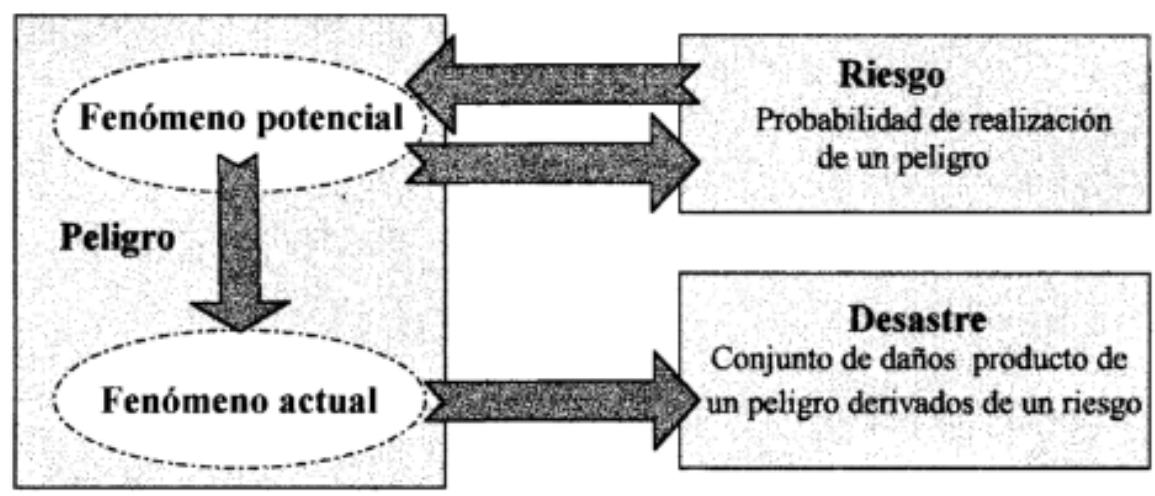

Fonte: CASTRO, 2000.

Figura 2: Relação entre os conceitos de Risco, Perigo e Desastre, numa perspectiva de descrever o primeiro como um fenômeno potencial e o último como um fenômeno concreto.

Dessa forma, e considerando as definições descritas, a Figura 3 apresenta um diagrama-resumo que, em nossa perspectiva, podem ser definidos os conceitos ora trabalhados.

\section{O que é vulnerabilidade? O que é susceptibilidade? O que é fragilidade?}

Diante das discussões acima expostas, é inerente associar ao debate os conceitos de vulnerabilidade, susceptibildiade, risco e desastre. Quanto à vulnerabilidade, a mesma é entendida como sendo a condição ou característica que expõe o elemento/sujeito (fator social) ao risco de ocorrência do evento indesejado (desastre, catástrofe, acidente, doença, degradação etc.). Alguém está em condição de vulnerabilidade. Entende-se que quanto a isso, há um consenso, ou seja, vulnerabilidade é uma condição social. É social porque se relacionada aos fatores bióticos, adéqua-se melhor o termo fragilidade.

É como Zanella (Et al., 2009, p. 192) explicita ao afirmar que vulnerabilidade é uma noção multidimensional, que pode surgir em virtude de fenômenos múltiplos, a partir de causas distintas, gerando consequências diversas, afetando diferenciadamente os variados grupos sociais. 
$\underline{\text { Risco }} \rightarrow$ situação onde um sujeito ou fator biótico/abiótico está exposto ao perigo;

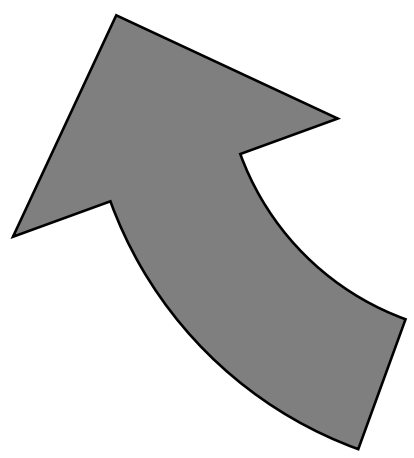

$\underline{\text { Vulnerabilidade } \rightarrow}$ condições ou características sociais que determinam a exposição de um sujeito, e o meio onde habita, ao risco.

\section{$\underline{\text { Susceptibilidade } \rightarrow}$} probabilidade do quanto um sujeito ou fator biótico/abiótico está exposto ao risco; $\underline{\text { Perigo }} \rightarrow$ ameaça ou as ações ou a ausência de ações preventivas que aumentam a susceptibilidade ao risco;

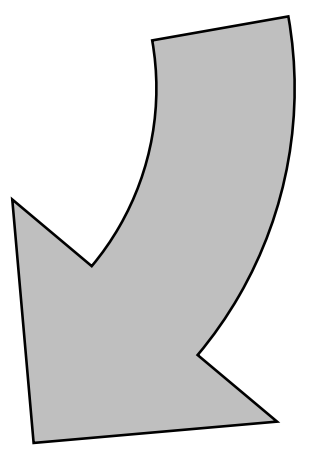

Fonte: próprio autor, 2016.

Figura 3: Diagrama de apresentação da síntese dos conceitos de Risco, Perigo e Susceptibilidade e suas influências na construção do conceito de Vulnerabilidade.

Susceptibilidade, como fator probabilístico, está relacionado à maior ou menor exposição ao risco, considerando os fatores de vulnerabilidade e fragilidade. Fragilidade, por sua vez, está relacionada as características naturais do ambiente que, em sendo menos resistentes aos eventos de alteração, expõem a área ao maior risco e/ou agentes de risco (SANTOS, 2011, p. 84).

A dimensão da interferência (efeito, que por sua vez entendemos ser o evento socioeconômico, sinistro, desastroso ou catastrófico) vai depender da estrutura socionatural do afetado, bem como da intensidade e características da ocorrência.

Nessa linha de pensamento, os riscos são considerados os cenários onde a susceptibilidade se manifesta mediante condições de vulnerabilidade e fragilidade. Entende-se que a existência de riscos associados considera a necessidade da existência de, pelo menos, um dos fatores: a) condições de vida da população e sua capacidade de resposta ao risco (Vulnerabilidade Social); b) o uso e a ocupação irregular dos espaços (fragilidade natural do ambiente); c) condições físicas e fatores sociais interagindo de forma desordenada 
ou em desacordo com as normas de proteção ambiental e de seguridade sanitária (Susceptibilidade e vulnerabilidade socioambiental ao risco).

Para Medeiros (2014), ao analisar-se a vulnerabilidade, enquanto metodologia e conceito, amplia-se a avaliação passando a considerar as potencialidade danosas do perigo. Assim, as condições físicas, sociais e culturais são levadas em consideração para determinar o quanto o sujeito sofre com os impactos nocivos de um perigo. Em outras palavras, ao confrontar a perspectiva da autora com a abordagem aqui explicitada, quer-se dizer, portanto, que o Perigo, enquanto ameaça, associado às condições/características do elemento, biótico ou não - susceptibilidade -, proporciona o risco, que pode efetivar-se ou não como desastre. O potencial de dano do perigo está intimamente relacionado à vulnerabilidade do local ou do grupo social, bem como à fragilidade do ambiente. Em suma, num determinado cenário, o potencial de perigo pode ser mensurado com vistas a identificação das situações de exposição ao risco. Esse mesmo potencial de perigo pode ser reduzido ou majorado, conforme caracteriza-se a vulnerabilidade/fragilidade (condições ambientais, sociais ou econômicas) e determina-se a susceptibilidade, reduzindo ou aumentando o risco (probabilidade de ocorrência do desastre).

Por exemplo, uma área de grande declividade caracteriza-se como o cenário de susceptibilidade que vai ser determinado de acordo com suas características de solo, de composição florestal, de grau de declividade etc. Conforme ocorre o desmatamento, ou substituição da vegetação primária, ou mesmo ocupação da área por habitações, estabelece-se o Perigo (ameaça) de ocorrência de fatores variados como perda da qualidade ambiental, deslizamento, morte etc., todos estes caracterizados como danos, ou tragédias, ou mesmo eventos infortúnios. O Risco será, portanto, a situação resultante da relação entre a área de declividade e as exposições às ameaças geradas pela intervenção.

\section{A perspectiva socioambiental e considerações finais}

Na década de 80, a ideia de vulnerabilidade estava muito mais próxima à ideia de capacidade e incapacidade, consolidando-se como uma espécie de método de mensuração do potencial de resposta frente às situações de Risco e exposição ao Perigo. Assim, vulnerabilidade era percebida um grau, no sentido de estágio escalonar, que mensura o quanto o ser humano é capaz de enfrentar o infortúnio. Dessa forma, subtende-se que a maior vulnerabilidade está posta na incapacidade humana de confrontar positivamente o evento danoso, corroborando-se como um potencial de perda, ao qual ninguém gostaria de estar susceptível. Vulnerabilidade enquanto a capacidade de sofrer danos e agir adversamente (KATES, 1985 apud CUTTER, 1996), vulnerabilidade enquanto grau de perda (UNDRO, 1982 apud CUTTER, 1996), vulnerabilidade enquanto incapacidade de tomar medidas eficazes contra perdas (BOGARD, 1989 
apud CUTTER, 1996), são expressões ditas por autores diversos que afirmar essa conotação dada ao conceito nessa época;

Na década de 90 em diante é notória a mudança no entendimento do conceito. Permanece uma associação íntima com os antônimos: capacidade e incapacidade, porém a ideia passa a estar associada à uma condição, características que torna o ser ou o elemento mais vulnerável ou menos vulnerável. Surge, ainda, uma primeira diferenciação entre os elementos naturais, sociais e econômicos, havendo, portanto, um reconhecimento de que a vulnerabilidade é posta como multidimensional e que integra fatores diversos. Assim, destacam-se as afirmações de Blaikie et al. (1994, apud CUTTER, 1996) que apresentam a vulnerabilidade como característica de uma pessoa ou grupo, considerando sua capacidade de resposta e diferenciando eventos na natureza e eventos na sociedade; Dow \& Downing (1995, apud CUTTER, 1996) que afirmam a susceptibilidade diferencial de circunstâncias que contribuem para existência do conceito; Cannon, Twigg \& Rowell (2003, apud THYWISSEN, 2006) que afirmam que o entendimento de vulnerabilidade é complexo e está associado ao conjunto de características; Klein (2003, apud THYWISSEN, 2006) que afirma ser o grau em que um sistema é sensível e incapaz de lidar com eventos negativos; e, Rashed \& Weeks (2003, apud THYWISSEN, 2006) que define como a fragilidade inerente a certos aspectos do ambiente.

Assim, e considerando as abordagens e entendimentos apresentados, sustentamos a ideia apresentada na figura 3 de que a vulnerabilidade caracteriza-se como as condições, características ou situações (naturais ou não) que determinam a exposição de um sujeito ou fator biótico/abiótico ao risco. Tal entendimento é uma base de definição que nos permitirá avançar na avaliação e determinação da vulnerabilidade, ampliando a análise e associando o conceito com outros elementos de definição como os termos fragilidade, sensibilidade, circunstância etc., a fim de proporcionar um avanço para planejamento de ambientes susceptíveis ao risco, que estejam expostos aos perigos diversos.

Resumidamente, temos: vulnerabilidade - o quanto um determinado componente está frágil, instável, diante de um determinado evento ou mesmo uma ordem natural, sendo que, atualmente, tal conceito é empregado em diferentes áreas, o que permite a existência de variações como a vulnerabilidade natural, social, econômica e socioambiental. A susceptibilidade pode ser diferenciada pela consideração de uma fragilidade específica ao qual o ambiente é sensível. Dessa forma, têm-se: Susceptibilidade à inundação, Susceptibilidade ao deslizamento etc.

O eixo de análise que envolve a sustentabilidade, preservação e planejamento ambiental deve levar em consideração os diversos aspectos naturais e do homem, numa perspectiva de interação interdisciplinar entre sociedade e natureza. Dessa forma, a complexidade da análise é sintetizada pela expressão 
socioambiental, numa tentativa de correlação entre os fatores naturais, sociais e as interferências em que um provoca no outro. Daí, trabalhar com o entendimento socioambiental consolida-se como uma estratégia ótima para que haja uma maior compreensão da realidade.

Por vulnerabilidade natural, associa-se ao estágio de estabilidade/instabilidade dos elementos físicos e bióticos, com as ordens de intensidade, dinâmica e magnitude da ação dos processos morfogenéticos, pedogenéticos e de fitossucessão, atuantes em cada unidade ecodinâmica (TRICART, 1977; GRIGIO, 2003 apud OLÍMPIO \& ZANELLA, 2012). Tagliani (2002 apud OLÍMPIO \& ZANELLA, 2012) considera ainda que a vulnerabilidade ambiental é a susceptibilidade do ambiente a um impacto provocado por um uso antrópico. Para Santos e Caldeyro (2007), a vulnerabilidade ambiental apresenta-se, ainda, como a capacidade de resposta às alterações humanas que afetam a qualidade ambiental. Há uma tendência atual pela adequação desse termo para a expressão fragilidade do ambiente.

A vulnerabilidade social, por sua vez, relaciona-se às condições de saúde, economia, educacional, política etc. que tornam as pessoas ou grupos sociais mais ou menos vulneráveis (ZANELLA et al, 2013, p. 320). Acerca da vulnerabilidade socioeconômica está a relação entre a fragilidade/instabilidade da sociedade, sua organização e ordem econômica, frente às mudanças, riscos e vulnerabilidades do ambiente natural e social produzido (OLÍMPIO \& ZANELLA, 2012).

Considera-se, portanto, que a vulnerabilidade humana e/ou ambiental está posta nas situações em que tanto um quanto outro estão (ou um ou outro está) prejudicados. Ou seja, quando uma perturbação é provocada de tal forma que resulta em efeitos adversos, especialmente, ao meio ambiente e a sociedade impactada. Dessa forma, vulnerabilidade socioambiental remete-se ao entendimento de incorporação entre a vulnerabilidade ambiental com a vulnerabilidade social (ZANELLA et al, 2013, p. 320).

Os efeitos adversos podem ser provocados por fatores de uso e ocupação irregular e inadequado da terra, disposição inadequada de componentes químicos e/ou biológicos no ambiente, bem como pelo consumo excessivo de recursos naturais, desconsiderando seus fatores de capacidade de suporte e entre outras variáveis associadas. Tais perturbações ao meio ambiente são provocadas por atividades e condições de vida humana que, ao desconsiderar os limites do meio ambiente, atuam de maneira incisiva e prejudicial. No entanto, a complexidade do tema está posto quando tais atividades, geradoras de perturbação, são provocadas pela existência de um sistema maior que condiciona tal forma de vida, sem abrir opções aos que provocam essa perturbação. Neste contexto, corrobora-se que na bacia hidrográfica está o espaço mais favorável para a percepção e aplicação do conceito de vulnerabilidade, tendo em vistas as características inerentes à mesma, frente às características dominantes no espaço geográfico. 


\section{Bibliografia}

ALMEIDA, L. Q. Por uma ciência dos riscos e vulnerabilidade na Geografia. Revista Mercator, v. 10, n. 23, p. 83-99, set./dez. 2011.

CASTRO, S. D. A. de. Riesgos y Peligros: una visión desde la geografia. Scripta Nova. Revista Electrónica de Geografia y Ciencias Sociales, n. 60. 15 marzo 2000. ISSN 1138-9788

JANCZURA, R. Risco ou vulnerabilidade social? Textos \& Contextos (Porto Alegre), v. 11, n. 2, p. 301 - 308, ago./dez. 2012.

CUTTER, A. C. Vulnerability to environmental hazards. Progress in Human Geography, v. 20, n. 4, p. 529-539. 1996.

LICCO, E. A.; SEO, E. S. M. Perigos e riscos naturais: estudo de caso do Jardim Pantanal. Revista Interfacehs. Vol. 8, n. 1, 2013. ISSN 1980-0894.

MENEZES JÚNIOR, E. M.; SILVA, O. G. da. Diferentes percepções para a compreensão do conceito de risco no enfoque ambiental. Revista Casa da Geografia de Sobral. v. 17, n. 2. p. 12-22. Jul. 2015.

NU. NACIONES UNIDAS. (Dpto de Asuntos Humanitarios, DHA). Prevención y mitigación de desastres. New York, UNDRO, 1984, Volumen 10. 145 pp.

SOUZA, L. B. e; ZANELlA, M. E. Percepção de Riscos Ambientais: Teoria e Aplicações. 2a Ed. Fortaleza: Edições UFC, 2010. 240 p.

VEYRET, Y.; RICHEMOND, N. M. O risco, o risco: Definições e vulnerabilidades do risco. In: VEYRET, Y. (Org.). Os riscos: o homem como agressor e vítima do meio ambiente. Trad. Dilson Ferreira. São Paulo: Contexto, 2007. 23-80. 